\title{
Approach to Occupational Contact Dermatitis in an Industrialized Region of Spain
}

Carvallo $\mathrm{A}^{1}$, Quan $\mathrm{P}^{1}$, Goikoetxea $\mathrm{MJ}^{1,2,3}$, Ferrer $\mathrm{M}^{1,2,3}$, Penella $\mathrm{J}^{1}$, Morales-Palacios MP' ${ }^{1}$, Gastaminza G ${ }^{1,2,3}$, D'Amelio $\mathrm{CM}^{1,2,3}$

${ }^{1}$ Department of Allergy and Clinical Immunology, Clinica Universidad de Navarra, Pamplona, Spain

${ }^{2}$ Spanish Research Network on Allergy RD 1600060031 (ARADyAL: Red Nacional de Alergia-Asma, Reacciones Adversas y Alérgicas) of the Carlos III Health Institute, Madrid, Spain

${ }^{3}$ Instituto de Investigación Sanitaria de Navarra (IdiSNA)

J Investig Allergol Clin Immunol 2021; Vol. 31(1): 73-75 doi: 10.18176/jiaci.0576

Key words: Occupational dermatitis. Allergic contact dermatitis. Irritant contact dermatitis. Contact allergy. Patch tests.

Palabras clave: Dermatitis ocupacional. Dermatitis de contacto alérgica. Dermatitis de contacto irritativa. Alergia de contacto. Pruebas epicutáneas.

Occupational contact dermatitis (OCD) is a skin condition characterized by the development of eczema due to contact with substances from the workplace. It is a frequent entity, with a known impact on quality of life and financial costs $[1,2]$. OCD can be classified as allergic, when the cause is sensitization to a known workplace allergen, or as irritant, when no contact sensitizations are found or these are not clinically relevant. Recent studies conducted in Spain reported a higher incidence of allergic OCD (between 53\% and $73 \%$ ) than irritant OCD $[3,4]$. The aim of this study was to determine the characteristics of patients with OCD and their most frequent sensitizations in a well-characterized population from a heavily industrialized region in northern Spain.

A retrospective study was conducted of all 45 patients evaluated by the Allergy Department of Clínica Universidad de Navarra, Pamplona, Spain between May 2017 and January 2020. The patients were clinically suspected of having OCD (compatible clinical presentation and temporal association between the skin lesions and workplace exposure to potential contact allergens). This evaluation included a complete occupational history, a physical examination, and patch testing with both the Spanish standard patch test series (Martí Tor Alergia SL) and specific allergens according to the patient's occupation and own products, when applicable [5]. All of the patients were from Navarre and the Basque Country, and most were referred to the department by mutual health insurance companies. Study variables were tested for normality using the Shapiro-Wilk test. Values for nonnormally distributed quantitative variables were presented as median (IQR), and comparative analyses were performed using the Mann-Whitney (Wilcoxon rank sum) test. A $P$ value $<.05$ was considered to be statistically significant. All statistical analyses were conducted using Stata/IC 15.1. The study was approved by the Research Ethics Committee of Universidad de Navarra. 
Of the 45 patients studied, $28(62.2 \%)$ were men and $17(37.8 \%)$ were women, with a mean (SD) age of 40 (11.2) years. A diagnosis of OCD was made in 35 cases $(77.8 \%) ; 8$ patients $(17.8 \%)$ were diagnosed with other skinrelated conditions, and results were inconclusive for a further 2 patients (4.4\%). Among the 35 cases of OCD, the cause was allergic in $25(71.4 \%)$ and irritant in $10(28.6 \%)$. A history of atopy (allergic rhinoconjunctivitis, extrinsic asthma, and atopic dermatitis) was present in $20 \%$ of OCD patients. The hands were the most frequently affected anatomic location (27 [77.1\%]), followed by the eyelids and surrounding area (9 $[25.7 \%])$ and the rest of the face (8 [22.9\%]). The occupation with the highest incidence of OCD was the automotive and mechanical industry $(31.4 \%)$, followed by the health and pharmaceutical industry (14.3\%). Most patients $(91.4 \%)$ used at least 1 form of protection, with gloves being the most frequent $(82.9 \%)$. Failure to use protection was identified in painters $(33 \%)$, the health and pharmaceutical industry $(20 \%)$, and the automotive and mechanical industry (9\%).

Among the patients with allergic OCD, the most frequent, clinically relevant sensitization was to epoxy systems $(9[36 \%])$, followed by formaldehyde and formaldehyde releasers $(4[16 \%])$, rubber additives $(3[12 \%])$, and paraphenylenediamine (3 [12\%]) (Table). Sensitization to epoxy systems was especially prevalent in workers from the automotive and mechanical industry, accounting for $50 \%$ of allergic OCD cases in this group. Median OCD latency (the time between initial allergen exposure and development of symptoms) seemed to be lower in patients with a history of atopy than in those without (6.4 [0.5-15.9] vs 23.5 [4-96] months, respectively); however, this difference was not statistically significant $(P=.14)$. Among the cases of allergic OCD, 7 (28\%) were compatible with airborne OCD.

The incidence of allergic OCD in the study population was higher than that of irritant OCD; this finding is compatible with those of recent studies conducted in Spain $[3,4]$. We detected a higher prevalence of OCD patients with a history of atopy $(20 \%)$ than reported in these studies $(15 \%$ and $8 \%$,

Table. Clinically Relevant Sensitizations Among Patients With Allergic Occupational Contact Dermatitis

\begin{tabular}{lc}
\hline Sensitization & No. $(\%)$ \\
\hline Epoxy systems & $9(36.0 \%)$ \\
$\quad$ Bisphenol A & $9(36.0 \%)$ \\
Diaminodiphenylmethane & $1(4.0 \%)$ \\
Formaldehyde and formaldehyde-releasers & $4(16.0 \%)$ \\
Rubber additives & $3(12.0 \%)$ \\
PPD & $3(12.0 \%)$ \\
Bioban P & $2(8.0 \%)$ \\
MI/MCI & $2(8.0 \%)$ \\
Metals & $2(8.0 \%)$ \\
Drugs & $2(8.0 \%)$ \\
Others & $3(12.0 \%)$ \\
\hline
\end{tabular}

Abbreviations: MCI, methylchloroisothiazolinone;

MI, methylisothiazolinone; PPD, paraphenylenediamine respectively). The role of pre-existing atopy-particularly atopic dermatitis - in the development of OCD has been discussed in the literature, with varied results depending on the allergen type $[6,7]$. We found no statistically significant differences in the latency period between atopic and nonatopic patients, although in atopic individuals, it seemed to be about 18 months lower than in nonatopic patients.

The most frequent cause of OCD in the study population was contact with epoxy systems (resins and hardeners), probably because most of the study population worked in the automotive and mechanical industry, where epoxy resins are a known sensitizer [4]. It is worth noting that, currently, the 2 industries with the highest income in Navarre are the automotive and wind power industries and that epoxy resins are a known cause of OCD in both of them $[4,8,9]$.

The automotive and mechanical industry was also one of the industries where incomplete protection was identified. This finding is worrying and highlights the need for effective health education in these workplaces, especially when it is known that sensitization to epoxy resins is usually clinically relevant [8]. Therefore, accurate education for workers is of the utmost importance if we are to prevent sensitization. Unfortunately, we were unable to record data for a series of factors, such as continued use of protective equipment, adequate removal (especially in the case of gloves, as removal sometimes exposes the clear skin directly to the allergen), and the quality of said equipment.

In conclusion, most cases of OCD in the present study were of allergic etiology. This finding, which is congruent with those of similar studies conducted in Spain, underlines the importance of performing allergy tests in this type of patient. Adequate health education should be provided in industry to improve the use and effectiveness of protective equipment as a means of lowering the risk and impact of developing OCD.

\section{Funding}

This study was supported by Instituto de Salud Carlos III (ISCIII) and cofunded by Fondo Europeo de Desarrollo Regional - FEDER for the Thematic Networks and Cooperative Research Centres: ARADyAL (RD16/0006/0031).

\section{Conflicts of Interest}

The authors declare that they have no conflicts of interest.

\section{Previous Presentation}

Data from this manuscript were presented as an oral communication at a meeting of the Spanish Society of Allergology and Clinical Immunology (Sociedad Española de Alergología e Inmunología Clínica), October 2019.

\section{References}

1. Kalboussi H, Kacem I, Aroui H, El Maalel O, Maoua M, Brahem $A$, et al. Impact of allergic contact dermatitis on the quality of life and work productivity. Dermatol Res Pract. 2019;2019:3797536. 
2. McCall BP, Horwitz IB, Feldman SR, Balkrishnan R. Incidence rates, costs, severity, and work-related factors of occupational dermatitis: a workers' compensation analysis of Oregon, 1990-1997. Arch Dermatol. 2005;141:713-8.

3. Subiabre-Ferrer $D$, Zaragoza-Ninet $V$, Ortiz-Salvador JM, Giacaman-von der Weth MM, Blasco-Encinas R, SierraTalamantes I. Dermatitis de contacto profesional, estudio clínico-epidemiológico entre los años 2011 y 2015. Med Segur Trab. 2016;62:318-26.

4. Holguín-Gómez L, Sastre Domínguez J. Occupational contact dermatitis in Spain. J Investig Allergol Clin Immunol. 2017;27:134-6.

5. Hervella-Garcés M, García-Gavín J, Silvestre-Salvador JF. The Spanish standard patch test series: 2016 update by the Spanish Contact Dermatitis and Skin Allergy Research Group (GEIDAC). Actas Dermosifiliogr. 2016;107:559-66.

6. Teo Y, McFadden JP, White IR, Lynch M, Banerjee P. Allergic contact dermatitis in atopic individuals: Results of a 30-year retrospective study. Contact Dermatitis. 2019;81:409-16.

7. Milam EC, Jacob SE, Cohen DE. Contact dermatitis in the patient with atopic dermatitis. J Allergy Clin Immunol Pract. 2019;7:18-26.

8. Bangsgaard N, Thyssen JP, Menné T, Andersen KE, Mortz CG, Paulsen E, et al. Contact allergy to epoxy resin: risk occupations and consequences. Contact Dermatitis. 2012;67:73-7.

9. Lárraga-Piñones $G$, Heras-Mendaza $F$, Conde-Salazar L. Occupational contact dermatitis in the wind energy industry. Actas Dermosifiliogr. 2012;103:905-9.

1 Manuscript received April 29, 2020; accepted for publication June 1, 2020

Gabriel Gastaminza

Av. Pio XII, 36

Clínica Universidad de Navarra 31008 Pamplona, Spain

E-mail: gastaminza@unav.es 